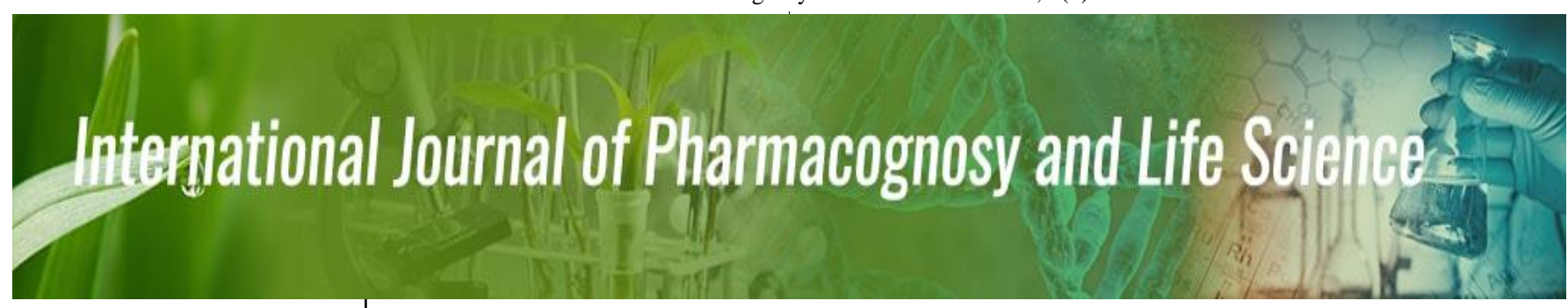

E-ISSN: $2707-2835$

P-ISSN: 2707-2827

IJPLS 2020; 1(2): 38-43

Received: 23-05-2020

Accepted: 26-06-2020

\section{Deepanshi Tiwari}

Research Scholar, Department of Pharmacology, Advance Institute of Biotech and Paramedical Sciences, Uttar Pradesh, India

\section{Mamta Tiwari}

Associated Professor

Department of Pharmacology, Advance Institute of Biotech and Paramedical Sciences

Uttar Pradesh, India
Corresponding Author: Deepanshi Tiwari Research Scholar, Department of Pharmacology, Advance Institute of Biotech and Paramedical Sciences, Uttar Pradesh, India

\section{Vincristine: Beyond on anticancer treatment}

\author{
Deepanshi Tiwari and Mamta Tiwari
}

DOI: $\underline{\text { https://doi.org/10.33545/27072827.2020.v1.i2a.17 }}$

\begin{abstract}
Vincristine is a chemotherapeutic agent that is a component of many combination regimens for a variety of malignancies, including several common pediatric tumors.78\% of patients with advanced malignant disease were treated with vincristine, an alkaloid derived from vinca rosea Linn, 59\% of these survived from the beginning of treatment and could be evaluated. Favourable responses were seen in patients with Hodking's disease, reticulum cell sarcoma, lymphosarcoma, carcinoma of the breast, acute leukemia and choriocarcinoma. Toxic include a high incidence of alopecia and neurologic complications. Vincristine treatment is limited by a progressive sensorimotor peripheral neuropathy. Vincristine-induced peripheral neuropathy (VIPN) is particularly challenging to detect and monitor in pediatric patients, in whom the side effect can diminish long term quality of life. Further research is needed to predict, prevent, and treat disease to maximize therapeutic benefit and avoid unnecessary toxicity from vincristine treatment.
\end{abstract}

Keywords: Vincristine, Catharanthus rosea Linn, hodking's disease, lymphosarcoma, vincristine induced peripheral neuropathy

\section{Introduction}

Vincristine is originally derived from the periwinkle plant Catharanthus roseus. Vincristine act as inhibitors during the metaphase of the cell cycle and by binding to the microtubules inhibit the development of the mitotic spindle ${ }^{[1]}$. The vinca alkaloids are important for being anticancer drugs like vincristine and vinblastine. The productivity of vinblastine and vincristine is very low in plants $(0.001-0.0003 \%)$ resulting in their extraordinary high price [2]. The United States Food and Drug Administration (FDA) approved indications of vincristine are acute lymphocytic leukemia, lymphoid blast crisis of chronic myeloid leukemia and Hodgkin and Non-Hodgkin lymphoma ${ }^{[3]}$. Vincristine also has several off-label uses that include central nervous system (CNS) tumors, Ewing sarcoma, gestational trophoblastic tumors, multiple myeloma, ovarian cancer, primary CNS lymphoma, small cell lung cancer, and advanced thymoma in adult patients ${ }^{[4]}$.

The productivity of vinblastine and vincristine is very low in plants $(0.001-0.0003 \%)$ resulting in their extraordinary high price. Vinblastine is a dimeric indole alkaloid and is formed by coupling of vindoline and catharanthine catalysed by horseradish peroxidase1. The yield of coupling products, $\left(15^{\prime} 20^{\prime}\right.$ - anhydro vinblastine) was reported very low $(0.9 \%)$ [5]. Vinblastine is converted into vincristine by the oxidation of its methyl group. Most of the key enzymes of the indole alkaloid biosynthetic pathway have been isolated from seedlings and/or cell suspension cultures of the C. roseus $2^{[6]}$. The cell cultures do not produce dimeric and monomeric indole alkaloids but catharanthine is produced in considerable amounts. Vincristine, vinblastine and vindoline were reported only in shoot cultures and differentiated tissues but not in roots ${ }^{[7]}$. Recently a stable, high producing and salt tolerant cell lines of $C$. roseus plant has been developed to achieve industrial production of the alkaloids. The major limitation of these drugs in cell cultures is their low yield. Particularly the improvement of catharanthine production in $C$. roseus cell cultures is of great interests for pharmacologists and chemists because catharanthine and vindoline can be coupled to form vinblastine in high yield, and vindoline is abundant in plants ${ }^{[8]}$. Elicitors can also modulate the production of these alkaloids as reported by Moreno et al. Involvement of metabolic engineering for alternative production methods was encouraged and made possible due to low vinblastine and vincristine contents in the plants ${ }^{[9,10]}$. Engineering techniques like semi-synthesis, total chemical synthesis or even of chemical ${ }^{[11,12]}$ or enzymatic coupling 13 of commercial 
available catharanthine a vindoline is useful plant.

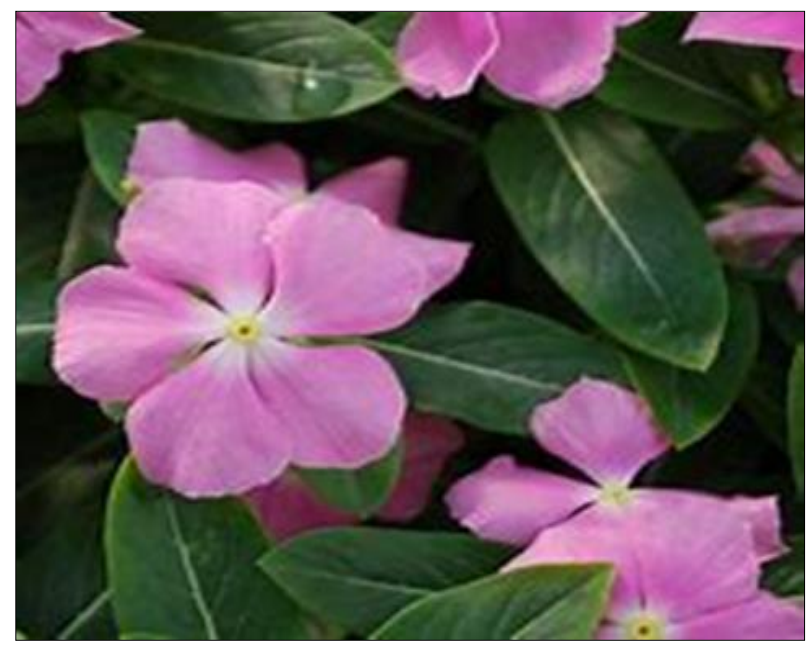

Fig 1: Vinca ${ }^{[13]}$

Vincristine is used in combination therapy to treat acute leukemias and lymphomas and constitutes an important component of the regime that has been so successful in treating childhood leukemias. Vinblastine is often used in combination to treat bladder and breast cancers and is an integral part of the curative treatment regime for Hodgkin's disease. Vinorelbine was approved for use in Europe (1991) and the U.S. (1995) for the treatment of non-small-cell lung cancer and vindesine has been approved for the treatment of melanoma [14]. Neurotoxicity (vincristine) or myelosuppression (vinblastine) are the main side effects of administration and neutropenia is the principal dose-limiting toxicity of the vinca alkaloids, but recovery occurs following treatment. However, the major limitation to the continued use of the vinca alkaloids is the emergence of drug resistance derived principally from over expression of phosphoglycoprotein (Pgp), an efflux pump that transports many of the major drugs out of the cell. In fact, vinblastine represents one of the most studied prototypical substrates for Pgp efflux responsible for multidrug resistance (MDR). Thus, in addition to identifying vinblastine and vincristine analogues that may address the current dose-limiting toxicities, the development of a modified vinca alkaloid that is not a substrate for Pgp efflux and is efficacious against MDR tumors would constitute a major advance [15, 16]. Additionally, the emerging evidence that the vinca alkaloids also possess antiangiogenic activity that may contribute to their in vivo antitumor activity, especially in combination with other drugs, may provide additional future clinical applications. Due to the pharmaceutical importance and low natural abundance of vinblastine and vincristine, $C$. roseus has become one of the most extensively studied medicinal plants serving as a model for biotechnological studies of plant secondary metabolism. Their biosynthesis involves the participation of at least 35 intermediates, 30 enzymes, 30 biosynthetic and 2 regulatory genes, and 7 intra- and intercellular compartments ${ }^{[9]}$. Presently, the clinical supplies of 1 and related drugs are derived from natural sources ${ }^{[17]}$. Fortunately, the doses are so small that the production amounts are manageable even with the trace natural abundance of $1(0.01 \%)$ or $2(0.0003 \%)$ in the source plants. Nonetheless, the effort required even for this limited quantity suggests that an efficient synthetic approach might provide a viable alternative. Even the development of an effective coupling protocol starting with the more abundant naturally occurring (+)-catharanthine $[18,10]$ and vindoline, vinpocetine, vincamine ${ }^{[19]}$ may supplant the direct use of plant produced vinblastine or vincristine. Interestingly, only $\mathrm{C}$. roseus produces catharanthine and does so with an absolute configuration enantiomer with structurally related alkaloids also found in C. roseus and related alkaloids found in nature. More significantly, an effective synthetic approach would provide access to analogues that incorporate deep-seated structural changes that have not yet been explored ${ }^{[20]}$. Typically, it has been semi synthetic derivatives of the natural products that have been examined, restricting the structural sites and opportunities to improve on the properties of 1 or $2^{[21]}$.

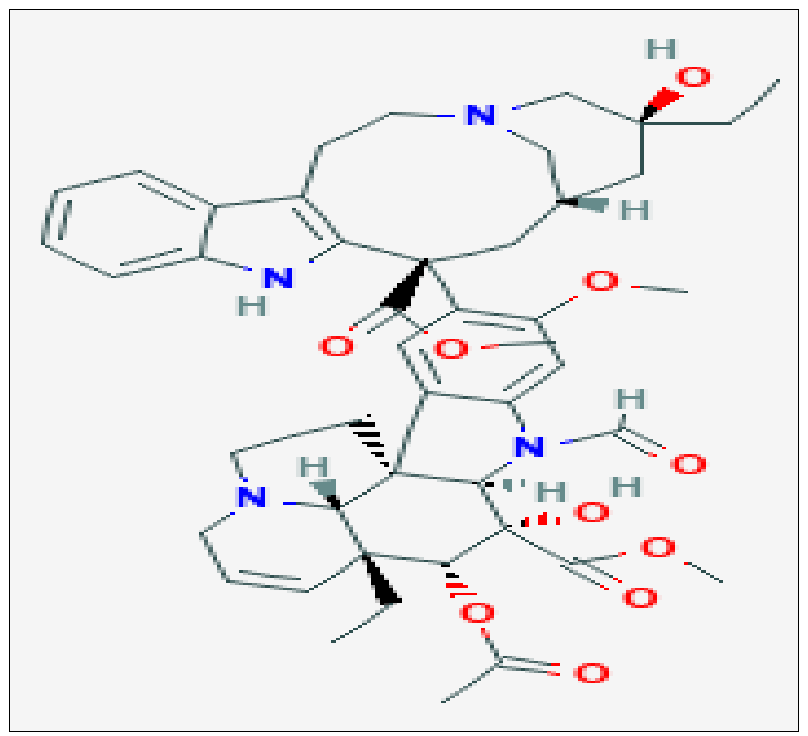

Fig 2: Vincristine

\section{Mechanism of action of vincristine}

Vincristine acts by binding to tubulin and inhibiting the formation of microtubules. This inhibition causes mitosis to arrest at metaphase, through the disruption of mitotic spindle formation, especially during the $\mathrm{M}$ and $\mathrm{S}$ phases ${ }^{[22,}$ 23]. Another mechanism of action of vincristine includes interfering with nucleic acid and protein synthesis by blocking glutamic acid utilization.

\section{Metabolism}

Vincristine is rapidly removed from the bloodstream and is tightly bound to tissues, but it poorly penetrates the bloodbrain barrier. Vincristine undergoes extensive metabolism in the liver via CYP3A4 [24]. Patients with serum bilirubin levels $>3 \mathrm{mg} / \mathrm{dl}$ will require dose adjustments; per the manufacturer's label, the dose in such patients should be $50 \%$ of the normally administered dose. Vincristine is excreted primarily in the feces.

\section{Pharmacological activity of vincristine on Hodking's disease}

Vincristine was found to be useful in the treatment of Hodgkin's disease reticulum cell sarcoma, lymphosarcoma, choriocarcinoma and to a minor degree in the treatment of some mammary tumours. It is generally ineffective in leukemias and in most carcinomas [25, 26]. Toxic effects include depression of erythropoiesis and granulopoiesis, frequent alopecia, occasional gastrointestinal toxicity and occasional neurological complications. 


\section{Antiviral effect}

The simplex herpes virus (type I) with a cytopathogenicity effect at $0.8 \mu \mathrm{g} / \mathrm{mL}$.Catharoseumine, a monoterpenoid indole alkaloid, has a unique peroxy bridge, which was identified as a potential inhibitor against falcipain-2 protozoa parasites (causes of malaria), showing an IC50 value of $4.06 \mu \mathrm{M}$. Vinblastine and vincristine showed an antiparasitic effect against Trypanosoma that causes trypanosomiasis in humans, inhibiting its mitosis and affecting its cellular shape in a dose-dependent manner ${ }^{[27]}$. The use of $15 \mu \mathrm{M}$ of vinblastine and $50 \mu \mathrm{M}$ of vincristine inhibited cellular division and cytokinesis, and affected cellular morphology, while the effect of $3 \mu \mathrm{M}$ of vinblastine and $10 \mu \mathrm{M}$ of vincristine inhibited cytokinesis without affecting cell cycle progression ${ }^{[28,29]}$.

\section{Antimicrobial activity}

Vincristine was tested against microorganisms such as Pseudomonas, Salmonella, Staphylococcus and thus, these extracts show promissory effects as prophylactic agents in the treatment of many diseases. Ramya et al. evaluated the in vitro antibacterial activity through the use of crude extracts of Catharanthus. The results indicated that leaf extracts showed a higher antibacterial activity than the extracts prepared from other parts of the Catharanthus plant. Thus, the aqueous extracts of leaves, stems, roots and flowers showed low microorganism growth ${ }^{[26,30]}$ tested leaf extracts of Catharanthus var. rosea, which showed an excellent activity against Aspergillus. Stem extracts of var. alba showed a maximum inhibitory activity against Bacillus while the flowers of Catharanthus var. rosea showed a higher activity against Bacillus in the methanolic extract ${ }^{[31]}$. The MIC (Minimal Inhibitory Concentration) against the tested microorganisms was in the range of $100-20 \mathrm{mg} / \mathrm{mL}$. In a different study, foliar acetonic, ethanolic, and chloroformic extracts were tested against pathogenic microorganisms to determine its antimicrobial potential ${ }^{[32]}$. The ethanolic extract showed the maximum antibacterial activity when compared to the acetonic and chloroformic extracts, in such a way that Staphylococcus was the most susceptible bacteria, followed by Escherichia, Pseudomonas and Streptococcus ${ }^{[33]}$.

\section{Anti-inflammatory activity}

Several factors have been suggested as possible predictors for VIN. A study from 2010 aimed to identify predictors for chemotherapy-induced peripheral neuropathy, including vincristine, in 52 patients ${ }^{[34]}$. It was discovered that the number of chemotherapy cycles was a predictor of VIN, whereas age and co-administration with non-steroidal antiinflammatory drugs did not correlate with neuropathy incidence and severity. Consistently, Anghelescu et al. observed no difference in age between ALL patients with or without neuropathy development ${ }^{[35]}$. No differences in sex, BMI group, initial leukocyte count, ALL immune phenotype, DNA index, or different genetic translocations were noted. The only significant clinical predictive variable observed was white non-Hispanic race ${ }^{[36]}$.

\section{Genotoxicity}

Previous studies have shown that Vinca alkaloids have the potential to induce genotoxic effects in different biological systems. The VCR and VBL have been shown to increase the frequency of micronuclei in experimental animals and in cultured human lymphocytes ${ }^{[37-40]}$. In addition, they have also been shown to cause chromosomal mutations in vivo and in cultured cancer cells [43, 45]. In cultured human lymphocytes, VRB and VCR increased the rate of micronucleus formation. In Drosophila, VCR and VBL induced a significant genotoxic effect as measured using wing somatic mutation and the recombination test [46]. However, some other studies have shown lack of mutagenic effect for Vinca alkaloids in vivo and in cultured cells ${ }^{[47-50]}$. Thus, the genotoxicity of Vinca alkaloids is still controversial. In addition, oxidative DNA damage induced by these compounds has still not been investigated

\section{Ocular toxicity}

Vincristine-induced ocular toxicity may be manifested as cranial nerve palsy, optic neuropathy/atrophy, or cortical blindness ${ }^{[51]}$. Depolarization of neurotubules by vincristine results in neurofibrillary degeneration and impairment of axonal transport ${ }^{[52]}$. Blindness may occur as the result of optic nerve ischemia, primary toxic axonal injury to the retinal nerve fiber layer, or disruption of microtubule polymerization ${ }^{[53]}$. The latter was also found to be associated with impairment of axoplasmic flow and loss of neurosynaptic activity in visual cells, resulting in night blindness.

\section{Production of cell culture and tissue culture}

The great pharmacological importance of the terpenoid indole alkaloids vincristine and vinblastine, associated to its low content in plants (approximately $0.0005 \%$ of dry weight), in vitro tissue and cell cultures, will permit the stimulation of intense research regarding the biosynthesis pathways of terpenoid indole alkaloids yet unknown through in vitro culture studies under biotic or abiotic elicitation strategies with the objective of increasing the production of C. roseus alkaloids ${ }^{[54,55]}$.

\section{L-ASP, and dexamethasone against acute lymphoblastic leukemia is enhanced by the BH3-mimetic ABT-737}

Several multiagent regimens, including the combination of vincristine, prednisone, and L-ASP, are reported to provide complete response (CR) rates of approximately $40 \%$ in multiple-relapse patients ${ }^{[6]}$. L-ASP, which depletes asparagine and glutamine in leukemic cells ${ }^{[11]}$, is a critical component of therapy for childhood ALL. As a single agent, L-ASP induced complete remissions in $40 \%$ to $60 \%$ of patients with ALL, and in combination with vincristine and prednisone is associated with an initial remission rate of 95\%.12,13 Both in vitro and in vivo resistance to L-ASP has been associated with poor long-term outcome ${ }^{[56]}$. In addition, relapsed patients with greater asparagine depletion on day 14 of re-induction were more likely to achieve a second remission in the context of 6-drug therapy ${ }^{[57]}$. However, expression of asparagine synthetase (AS), which may oppose the action of L-ASP by re-synthesis of asparagine, has varied widely in clinical ALL samples, but a relationship of AS levels to drug resistance has not been reported ${ }^{[58,59]}$. ABT-737 is a small molecule that binds to and inhibits the Bcl-2 family anti-apoptotic proteins BclXL, Bcl-2, and Bcl-w. Similar to the BH3-only "sensitizing" protein Bad, ABT-737 does not directly activate Bax or Bak or induce cytochrome c release. Instead, ABT-737 binds to multidomain antiapoptotic Bcl-2 family proteins, preventing them from sequestering proapoptotic $\mathrm{BH} 3$-only 
proteins.18,19 Overexpression of anti-apoptotic Bcl-2 (Bcl2 and $\mathrm{Bcl}-\mathrm{XL}$ ) family proteins has been observed in acute myeloid leukemia (AML) ${ }^{[20-22]}$, ALL [23, 24], and other cancers ${ }^{[60]}$. Bcl-XL overexpression has been reported as an independent predictor of poor event-free survival (EFS) in pediatric ALL ${ }^{[61]}$. Effective pharmacologic inhibition of the Bcl-2 family of proteins could lower the apoptotic threshold in leukemia cells, resulting in synergy with other chemotherapeutic agents, including drugs commonly used for remission induction in primary and relapsed leukemia, such as vincristine, glucocorticoids, and L-ASP. Using both in vitro and in vivo models of ALL, we investigated the potential for synergistic activity of ABT-737 in combination with vincristine, L-ASP, and dexamethasone (VXL), drugs commonly used.

\section{Anti-tumour activity}

Different percentages of the crude methanolic extracts have been found to show significant anticancer activity against several cell types under in vitro conditions and with a high activity against multidrug-resistant tumor types ${ }^{[62]}$. On the other hand, Ruskin and Aruna showed that the ethanolic extract of vincristine has in vivo antitumor activity in the Ehrlich carcinoma tumor model, while the in vitro study of the ethanolic extract showed significant antitumor activity

\section{Antileukemic activity}

Vincristine is employed to treat lymphocytic acute leukemia (the most frequent malign homeopathy in childhood), of which several chromosomic alterations with prognostic importance are known. Among them there are the translocation $[4,11]$ and the translocation $[9,22]$ which are indicators of a bad prognosis, while hyperdiploidy is associated with a good prognosis [63, 64] and it attacks lymphomas including solid tumours in children.

\section{Antioxidant enzymatic activity}

An experiment with different concentrations of sodium chloride in two varieties of Catharanthus (var. alba and rosea) was carried out ${ }^{[65]}$. It was found that the enzymatic activity of the superoxide dismutase increased, at levels of $50 \mathrm{mM}$ of sodium chloride, which helps to raise the levels of this enzyme with antioxidant value ${ }^{[66]}$.

\section{Hematologic activity}

Overall survival for adult hematologic cancer patients has improved during the past decades due to new treatment options, and more than $80 \%$ of children with acute lymphoblastic leukemia (ALL) are now long-term survivors [67]. This therapeutic success, however, comes with the cost of more people experiencing early and late-onset adverse effects, consequently affecting the recovering patient's QOL, which is especially important in children with a long expected lifespan after treatment. Although the intensity of the symptoms may not be extensive, the inconvenience is not correlated, and QOL can be greatly impaired ${ }^{[68]}$. Given the increasing numbers of cancer survivors, the clinical significance of chemotherapy-induced neuropathy is increasing; consequently, clinical and molecular risk predictors, prevention and treatment options, and measuring methods are urgently warranted ${ }^{[69]}$. In this paper, we systematically review parameters related to vincristineinduced neurotoxicity in hematologic patients ${ }^{[70]}$.

\section{Conclusion}

The vincristine is anticancer drugs that act by binding to intracellular tubulin. In tumour cells, vincristine and vinblastine inhibit the DNA repair and the RNA synthesis mechanisms, blocking the DNA-dependent RNA polymerase ${ }^{[71,72]}$. C. roseus is an important medicinal plant with several applications in pharmaceutical and industrial products. In the present, vincristine is alkaloids for the treatment of childhood leukemia and Hodgkin lymphoma. Production rate of vincristine in C. roseus is very low, its extraction costly, and too inefficient to be industrialized ${ }^{[73]}$. The semi-synthesis also faces many obstacles because of the necessary presence of precursors and intermediaries ${ }^{[74]}$. The great pharmacological importance of the terpenoid indole alkaloids vincristine, associated to its low content in plants (approximately $0.0005 \%$ of dry weight), in vitro tissue and cell cultures, will permit the stimulation of intense research regarding the biosynthesis pathways of terpenoid indole alkaloids yet unknown through in vitro culture studies ${ }^{[75]}$. Here, I conclude that vincristine has wide variety of pharmacological activity including cancer, further, studies, experiment and research give more pharmacological activity of vincristine.

\section{Acknowledgement}

Primarily I would thank God for being able to complete this review with success. Then I would like to thank my coguide Mrs. Mamta Tiwari and all the author of this review, whose valuable guidance has been helped me to patch his review and make it full proof.

\section{Conflict of interest}

None.

\section{Contribution}

All authors participated equally.

\section{Reference}

1. Zhou X, Xu Z, Li A, Zhang Z, Xu S. Double-sides sticking mechanism of vinblastine interacting with $\alpha, \beta$ tubulin to get activity against cancer cells. J Biomol Struct Dyn 2019;37(15):4080-4091.

2. Pernot B, Gyan E, Maillot F, Hodges P, Ertault M, Ferreira-Maldent N. Lymphomas diagnosed in an internal medicine department compared to lymphomas diagnosed in other departments: Clinical and outcome differences. Medicine (Baltimore) 2018;97(47):e13228.

3. Schiller GJ, Damon LE, Coutre SE, Hsu P, Bhat G, Douer D. High-Dose Vincristine Sulfate Liposome Injection, for Advanced, Relapsed, or Refractory Philadelphia Chromosome-Negative Acute Lymphoblastic Leukemia in an Adolescent and Young Adult Subgroup of a Phase 2 Clinical Trial. J Adolesc Young Adult Oncol 2018;7(5):546-552.

4. Martino E, Casamassima G, Castiglione S, Cellupica E, Pantalone S, Papagni F, Rui M, Siciliano AM, Collina S. Vinca alkaloids and analogues as anti-cancer agents: Looking back, peering ahead. Bioorg Med Chem Lett 2018;28(17):2816-2826.

5. Goodbody A, Endo A, Vukovic TJ, Misawa M. The coupling of catharanthine and vindoline to form 3', 4'anhydrovinblastine by haemoproteins and haemin. Planta Med 1988;54:210-214. 
6. Kutchan M. Alkaloid biosynthesis-The basis for metabolic engineering of medicinal plants. The Plant Cell 1995;7:1059-1070.

7. De Luca V, Fernandez JA, Campbell D, Kurz WGW. Developmental regulation of enzymes of indole alkaloid biosynthesis in Catharanthus roseus. Plant Physiol 1988;86:447-450

8. Goodbody A, Endo T, Misawa M. Alkaloid production in root and shoot cultures of Catharanthus roseus. Plant Med 1987;53:479-482.

9. Neuss N, Neuss MN. In The Alkaloids; Brossi, A., Suffness, M., Eds.; Academic: San Diego 1990;37:229.

10. Noble RL, Beer CT, Cutts JH, Ann NY. Acad. Sci. 1958, 76, 882. (b) Noble, R. L. Lloydia 1964;27:280.

11. Mangeney P, Andriamialisoa RZ, Lallemand JY, Langlois N, Langlois Y, Potier P. Tetrahedron 1979;35:2175.

12. Andriamialisoa RZ, Langlois N, Langlois Y, Potier P. Tetrahedron 1980;36:3053.

13. Anubhav Dubey, Deepanshi Tiwari, Kshama Srivastava, Om Prakash, Rohit Kushwaha. A discussion on vinca plant. J Pharmacogn Phytochem 2020;9(5):2731

14. Fahy J, Dulfos A, Ribet JP, Jacquesy JC, Berrier C, Jouannetaud MP, Zunino FJ. Am. Chem. Soc 1997;119:8576.

15. Hill BT, Fiebig HH, Waud WR, Poupon MF, Colpaert F, Kruczynski A. Eur. J Cancer 1999;35:512.

16. Hill SA, Lonergan SJ, Denekamp J, Chaplin DJ. Eur. J Cancer 1993;29:1320.

17. Baguley BC, Holdaway KM, Thomsen LL, Zhuang L, Zwi LJ. Eur. J Cancer 1991;27:482.

18. Vacca A, Iurlaro M, Ribatti D, Minschetti M, Nico B, Ria R, Pellegrino A, Dammacco F. Blood 1999;94:4143.

19. Dubey Anubhav, Tiwari M, Singh Yatendra, Kumar N, Srivastava K. Investigation of anti-Pyretic activity of vinpocetine in wistar rat, International Journal of Pharmaceutical Research 2020;12(2):1901-1906.

20. Dubey A, Kumar R, Kumar S, Kumar N, Mishra A, Singh Y, Tiwari M. Review onVinpocetine, Int. J of Pharm. \& Life Sci 2020;11(5):6590-6597.

21. Misawa M, Goodbody AE. Production of antitumor compounds by plant cell cultures. In: Dicosmo, F; Misawa, M., eds. Plant cell culture and secondary metabolism toward industrial application. New York: CRC Press 1996, P123-138.

22. Moreno PRH, Heijden VR, Verpoote R. Cell and tissue cultures of Catharanthus roseus: a literature survey. Plant cell, tissue and organ culture 1995;42:1-7.

23. Munier F, Perentes E, Herbort CP, Uffer S, Biollaz J. Selective loss of optic nerve beta tubulin in vincristineinduced blindness. Am J Med 1992;93(2):232-234.

24. Rosenthal S, Kaufman S. Vincristine neurotoxicity. Ann Intern Med 1974;80(6):733-737.

25. Byrd RL, Rohrbaugh TM, Raney RB Jr, Norris DG. Transient cortical blindness secondary to vincristine therapy in childhood malignancies. Cancer 1981;47(1):37-40.

26. Ripps H, Carr RE, Siegel IM, Greenstein VC. Functional abnormalities in vincristine-induced night blindness. Invest Ophthalol Vis Sci 1984;25(7):787794.
27. Tiburi M, Reguly ML, Schwartsmann G, Cunha KS, Lehmann M, Rodrigues de Andrade HH. Comparative genotoxic effect of vincristine, vinblastine, and vinorelbine in somatic cells of Drosophila melanogaster. Mutat Res 2002;519(1-2):141-149.

28. Gundy S, Baki M, Bodrogi I. Vinblastine, cisplatin and bleomycin (VPB) adjuvant therapy does not induce dose-dependent damage in human chromosomes. Neoplasma 1989;36(4):457-464.

29. Morgan WF, Crossen PE. A comparison of induced sister chromatid exchange levels in Chinese hamster ovary cells and cultured human lymphocytes. Environ Mutagen 1982;4(1):65-71.

30. The Effect of Vincaleukoblastine on Dividing Cells in Vise. Cancer Res 1961;21:168.

31. Ernwri J, DuaTni P, JR. Colchicine in Agricul ture, Medicine, Biology, and Chemistry. Ames, Iowa: The Iowa State CollegePress 1955.

32. Gonzalez-Cid M, Cuello MT, Larripa I. Mitotic arrest and anaphase aberrations induced by vinorelbine in hamster cells in vitro. Anticancer Drugs 1997;8(5):529. 532.

33. Alzoubi K, Khabour O, Khader M, Mhaidat N, AlAzzam S. Evaluation of vitamin B12 effects on DNA damage induced by paclitaxel. Drug Chem Toxicol 2014;37(3):276-280

34. Alzoubi K, Khabour O, Hussain N, Al-Azzam S, Mhaidat M. Evaluation of vitamin B12 effects on DNA damage induced by pioglitazone. Mutat Res 2012;748(1-2):48-51.

35. Alsatari ES, Azab M, Khabour OF, Alzoubi KH, Sadiq MF. Assessment of DNA damage using chromosomal aberrations assay in lymphocytes of waterpipe smokers. Int J Occup Med Environ Health 2012;25(3):218-224.

36. Khabour OF, Alsatari ES, Azab M, Alzoubi KH, Sadiq MF. Assessment of genotoxicity of waterpipe and cigarette smoking in lymphocytes using the sisterchromatid exchange assay: A comparative study. Environ Mol Mutagen 2011;52(3):224-228.

37. Alzoubi KH, Khabour OF, Jaber AG, Al-Azzam SI, Mhaidat NM, Masadeh MM. Tempol prevents genotoxicity induced by vorinostat: role of oxidative DNA damage. Cytotechnology 2014;66(3):449-455.

38. Fraunfelder FT, Meyer SM. Ocular toxicity of antineoplastic agents. Ophthalmology 1983;90(1):1-3.

39. Albert DM, Wong VG, Henderson ES. Ocular complications of vincristine therapy. Arch Opthalmol 1967;78(6):709-713.

40. Schochet SS, Lampert PW, Earle KM. Neuronal changes induced by intrathecal vincristine sulphate. J Neuropathol Exp Neurol 1968;27(4):645-658.

41. Bargallo N, Burrel M, Berenguer J, Cofan F, Bunesch L, Mercader JM. Cortical laminar necrosis caused by immunosuppressive therapy and chemotherapy. Am J Neuroradiol 2000;21(3):479-484.

42. Nelson RL. The comparative clinical pharmacology and pharmacokinetics of vindesine, vincristine and vinblastine in human patients with cancer. Med Pediatr Oncol 1982;10(2):115-127.

43. Potarazu SV. Ischemic optic neuropathy: models for mechanism of disease. Clin neurosci 1997;4(5):264269. 
44. Dunker S, Hsu HY, Sebag J, Sadun AA. Perioperative risk factors for posterior ischemic optic neuropathy. $\mathrm{J}$ Am Coll Surg 2002;194(6):705-710.

45. Hayreh SS. Ischemic Optic Neuropathy. Prog Retin Eye Res 2009;28(1):34-62.

46. Buono LM, Foroozan R. Perioperative posterior ischemic optic neuropathy: review of the literature. Surv Ophthalmol 2005;50(1):15-26.

47. Ozcelik B, Kartal M, Orhan I. Cytotoxicity, antiviral and antimicrobial activities of alkaloids, flavonoids, and phenolics acids. Pharmaceutical Biology 2011;49:396402.

48. Ruskin RS, Aruna SR. In-vitro and in-vivo antitumor activity of Catharanthus roseus. International Research Journal of Pharmaceutical and Applied Sciences 2014;4:1-4

49. Kyakulaga A, Hassan AT, Brenda VP. In vivo antidiarrheal activity of the ethanolic leaf extract of Catharanthus roseus Linn. (Apocynaceae) in Wistar rats. African Journal of Pharmacy and Pharmacology 2011;5:1797-1800.

50. Kumari K, Gupta S. Antifungal properties of leaf extract of Catharanthus roseus L (g.) Don. American Journal of Phytomedicine and Clinical Therapeutics 2013;1:698-705.

51. Ramya S, Govindaraji V, Navaneetha KK, Jayakumararaj R. In vitro evaluation of antibacterial activity using crude extracts of Catharanthus roseus L. (G.) Don. Ethnobotanical Leaflets 2008;12:1067-1072.

52. Tjalma W, Weyler J, Goovaerts G et al. Prognostic value of bcl-2 expression in patients with operable carcinoma of the uterine cervix. J Clin Pathol 1997;50:33-36.

53. Gruhn B, Hongeng S, Yi $\mathrm{H}$ et al. Minimal residual disease after intensive induction therapy in childhood acute lymphoblastic leukemia predicts outcome. Leukemia 1998;12:675-681.

54. Sheard MA, Kang MH, Cabral D et al. Bone marrowlevel oxygen tension enables enhanced and sustained growth of 3 new pediatric acute lymphoblastic leukemia cell lines [abstract]. Proc Am Assoc Cancer Res 2007;48:1808.

55. O’Donnell PH, Guo WX, Reynolds CP, Maurer BJ. N(4-hydroxyphenyl) retinamide increases ceramide and is cytotoxic to acute lymphoblastic leukemia cell lines, but not to non-malignant lymphocytes. Leukemia 2002;16:902-910.

56. Stong RC, Korsmeyer SJ, Parkin JL, Arthur DC, Kersey JH. Human acute leukemia cell line with the $\mathrm{t}$ (4; 11) chromosomal rearrangement exhibits B lineage and monocytic characteristics. Blood 1985;65:21-31.

57. Brown JM, Lemmon MJ. Tumor hypoxia can be exploited to preferentially sensitize tumors to fractionated irradiation. Int $\mathbf{J}$ Radiat Oncol Biol Phys 1991;20:457-461.

58. Grigoryan R, Keshelava N, Anderson C, Reynolds CP. In vitro testing of chemosensitivity in physiological hypoxia. Methods Mol Med 2005;110:87-100.

59. Masters JR, Thomson JA, Daly-Burns B et al. Short tandem repeat profiling provides an international reference standard for human cell lines. Proc Natl Acad Sci USA 2001;98:8012-8017.

60. Keshelava N, Frgala T, Krejsa J, Kalous O, Reynolds CP. DIMSCAN: a microcomputer fluorescence-based cytotoxicity assay for preclinical testing of combination chemotherapy. Methods Mol Med 2005;110:139-153.

61. Frgala T, Kalous O, Proffitt RT, Reynolds CP. A novel cytotoxicity assay with a $4 \log$ dynamic range that identifies synergistic drug combinations. Mol Cancer Ther 2007;6:886-897.

62. Bedikian AY, Vardeleon A, Smith T, Campbell S, Namdari R. Pharmacokinetics and urinary excretion of vincristine sulfate liposomes injection in metastatic melanoma patients. J Clin Pharmacol 2006;46:727-737.

63. Boos J. Pharmacokinetics and drug monitoring of Lasparaginase treatment. Int $\mathbf{J}$ Clin Pharmacol Ther 1997;35:96-98.

64. Brady ME, Sartiano GP, Rosenblum SL, Zaglama NE, Bauguess CT. The pharmacokinetics of single high doses of dexamethasone in cancer patients. Eur J Clin Pharmacol 1987;32:593-596.

65. Hawkins DS, Park JR, Thomson BG et al. Asparaginase pharmacokinetics after intensive polyethylene glycol-conjugated L-asparaginase therapy for children with relapsed acute lymphoblastic leukemia. Clin Cancer Res 2004;10:5335-5341.

66. Nelson RL. The comparative clinical pharmacology and pharmacokinetics of vindesine, vincristine, and vinblastine in human patients with cancer. Med Pediatr Oncol 1982;10:115-127.

67. Diaz GD, Li Q, Dashwood RH. Caspase-8 and apoptosis-inducing factor mediate a cytochrome cindependent pathway of apoptosis in human colon cancer cells induced by the dietary phytochemical chlorophyllin. Cancer Res 2003;63:1254-1261.

68. Liem NL, Papa RA, Milross CG et al. Characterization of childhood acute lymphoblastic leukemia xenograft models for the preclinical evaluation of new therapies. Blood. 2004;103:3905-3914.

69. Chou TC, Talalay P. Generalized equations for the analysis of inhibitions of Michaelis-Menten and higherorder kinetic systems with two or more mutually exclusive and nonexclusive inhibitors. Eur J Biochem. 1981;115:207-216.

70. Kaplan EL, Meier P. Nonparametric estimation from incomplete observations [abstract]. Am Stat Assoc J 1958;53:457-481.

71. Datta SR, Katsov A, Hu L et al. 14-3-3 proteins and survival kinases cooperate to inactivate $\mathrm{BAD}$ by $\mathrm{BH} 3$ domain phosphorylation. Mol Cell 2000;6:41-51.

72. Zha H, Reed JC. Heterodimerization-independent functions of cell death regulatory proteins Bax and Bcl2 in yeast and mammalian cells. J Biol Chem 1997;272:31482-31488.

73. Soysal T, Ferhanoglu B, Bilir M, Akman N. Oculomotor nerve palsy associated with vincristine treatment. Acta Haematol 1993;90(4):209-210.

74. Lash SC, Williams CPR, Marsh CS, Crithchley C, Hodgkins PR, MacKie EJ. Acute sixth-nerve palsy after vincristine therapy. J AAPOS 2004;8(1):67-68.

75. Toker E, Yenice O, Ogut MS. Isolated abducens nerve palsy induced by vincristine therapy. J AAPOS 2004;8(1):69-71. 